\title{
Prática de ensino de física: a ANÁlise do discurso COMO BASE PARA INTERPRETAÇÃO DE RELATÓRIOS DE ESTÁGIO DE REGÊNCIA ${ }^{1}$
}

\author{
Physics teaching practice: discourse analysis as basis to \\ INTERPRET FUTURE TEACHERS' REPORTS \\ Sérgio Camargo* \\ Roberto Nardi \\ Iracema B. Torcuato **
}

\begin{abstract}
Resumo
A pesquisa aqui relatada foi desenvolvida no âmbito da formação inicial de professores e teve como meta avaliar o impacto de um curso estruturado de Prática de Ensino numa amostra de alunos do Curso de Licenciatura em Física, quando submetidos à situação de estágio de regência. A interpretação dos discursos presentes nos relatórios de regência elaborados ao final do estágio, mostra, dentre outros aspectos, que a ideologia implícita no discurso do futuro professor reforça o paradigma da racionalidade técnica, muito embora os enunciadores dos discursos analisados tenham tentado apresentar os conteúdos de acordo com referenciais teóricos previamente estudados. Em vários excertos analisados persiste explicitamente uma dissociação entre teoria e prática. Esses dados, bem como outros obtidos na pesquisa, podem subsidiar discussões para repensar a formação inicial e continuada de professores de Física.

Palavras Chaves: Formação Inicial de Professores de Física, Prática de Ensino de Física, Análise do Discurso
\end{abstract}

\section{Abstract}

We report here a research, undertaken among future High School Physics teachers, which aimed to evaluate the effect of a structured Teaching Practice course in a sample of 22 students exposed to a teaching practice experience. Data collected from the reading of

${ }^{1}$ Apoio: Coordenação de Aperfeiçoamento de Pessoal de Nivel Superior (CAPES)

*scamargo@fc.unesp.br

** Grupo de Pesquisa em Ensino de Ciências - Professor Adjunto - Depto. de Educação - Programa de Pós-graduação em Educação para a Ciência - UNESP - Faculdade de Ciências - Câmpus de Bauru, São Paulo, Brasil. Apoio: CNPq - Conselho Nacional de Pesquisa. nardi@fc.unesp.br

*****ira_torquato@uol.com.br 


\begin{abstract}
their academic reports made after finishinf the teaching experience show, among other aspects, that the ideology implicity in the discourse of these future teachers reinforce the techinical rationality paradigm, even though the analyzed discourses' enunciators have intended to present the contents according to theroretical referentials previously studied. In various excerts analyzed persist the dissociation between practice and theory. These data collected, as well as other obtained during the research can subside discussions to rethink teacher professional development.
\end{abstract}

Key words: Physics Teachers Eduation; Physics Teaching Practice, Discourse Analysis

\section{INTRODUÇÃO}

Discutir a formação do professor implica a valorização de sua prática, reconhecendo que essa reflexão é fonte de conhecimento sobre o desenvolvimento profissional do docente. É através da consciência crítica sobre sua experiência que o professor emancipa-se de suas práticas rotineiras. A experiência é concebida, desse modo, como um processo contínuo de formação e (re)construção pessoal e profissional. A literatura sobre formação de professores tem ressaltado, nas últimas décadas, a necessidade do professor assumir o papel de investigador de sua própria prática, adotando uma postura ativa, ressignificando sua ação.

Dentre esses estudos torna-se imprescindivel tomar como referência os trabalhos desenvolvidos por Schön (1992; 2000) a respeito do profissional "como prático autônomo, que pensa, que toma decisões e que cria, durante a sua própria ação", em contraste àquele considerado "como técnico especialista que aplica com austeridade as regras que derivam do conhecimento científico".
Ao criticar o modelo hegemonicamente dominante, Schön (1992) ressalta o ressurgimento, nas universidades, do profissional formado sob o ponto de vista da racionalidade técnica, em que o ensino é considerado como uma ciência aplicada, e o professor exerce o papel de um técnico (Schön, 1992, 2000; Pérez Gómez, 1992; Carvalho, 2001) que domina as normas de aplicação do conhecimento científico, cabendo a ele somente aplicar os conhecimentos produzidos por outros.

Contrariamente a este modelo, propõe -como alternativa- uma epistemologia da prática, fundamentada na reflexão sobre a ação. Dessa forma, argumenta que os saberes baseados na racionalidade técnica não são suficientes para enfrentar a diversidade das situações de ensino e aprendizagem necessitando, de modo seminal, refletir sobre novas formas de ensinar.

Segundo a perspectiva educacional da racionalidade técnica, os professores podem agir sem levar em conta o "fazer" e o "como fazer". Atuam conforme as determinações das instâncias superiores e sobre aquilo que os especialistas de- 
finem. Obstaculiza-se, assim, o caminho para a autonomia, tanto das instituições, quanto dos professores, fechando novas formas de agir e atribuir significados às experiências inovadoras.

Schon (1992) salienta que geralmente existem parâmetros estipulados pelo governo, por meio de regulamentações previamente elaboradas, de forma que as instituições periféricas são induzidas a moldar seus relatórios de acordo com tais especificações. A conseqüência desse tipo de orientação à formação dos professores não poderia ser outra senão a de se estabelecer estagnação ao desenvolvimento da prática docente, uma vez que a racionalidade técnica ignora as competências requeridas em situações divergentes, assim como a natureza, os conteúdos e a estrutura dos programas de formação. Cria-se uma resistência à mudança, uma vez que o professor habitua-se a lecionar sempre do mesmo jeito, seguindo pressupostos estabelecidos sem refletir; está, na verdade, sendo um mero repetidor de tais orientações. Portanto, é necessário ocorrer uma mudança, tornando possível que ações engendradas em objetivações preestabelecidas possam adquirir subjetivações profícuas, implicando, dessa forma, uma visão construtiva do conhecimento.

É justamente neste sentido que Schön (1992, 2000) refere-se ao profissional prático reflexivo, que ostenta um papel ativo na construção de seu saber. A importância do conhecimento adquirido na ação é enfatizada por Schön (1992), ao criticar o conhecimento escolar, caracterizado pela pre- visibilidade e pelo controle, alertando para o fato de o conhecimento ser tratado como se existisse numa única via, engendrando uma exclusiva resposta, exata e inquestionável. Esse pensamento não corresponde à verdade, pois o conhecimento pode se manifestar de várias formas. Assim, a reflexão "na" e "pela" ação é implícita e surge junto com a própria ação; ou seja, esta reflexão decorre simultaneamente à própria situação, não implicando necessariamente uma expressão verbal, de mão única. Esse autor refere-se também à importância da confusão e da incerteza, sendo impossível aprender sem se ficar confuso. Esta atitude de reconhecer o valor da confusão e da incerteza, conduz a uma negação de que o saber é constituído por proposições firmadas na seqüência de pesquisas, e que ele é definido com o aval de "autoridades científicas".

Segundo Schön (1992), portanto, "o grande inimigo da confusão é a resposta que se assume como verdade única". Assim, se só houver uma única resposta certa, na suposição do professor, como forma de se saber aquilo que o aluno deve, ou não, aprender, então se estará negando a legitimidade para a "confusão" ser engendrada.

Portanto, é necessário respeitar os professores como profissionais, e mostrar que fazem parte de um sistema complexo, mas que não precisam (nem devem) se deixar moldar por ele.

Existe a possibilidade de transformar o sistema vigente e, nessa transformação, novas oportunidades surgirão para se entender o contexto em que es- 
tão inseridos os alunos e os professores; desse modo, há aberturas para ressignificar e inovar as práticas pedagógicas. Incentiva-se, assim, o surgimento de uma competência pedagógica, pautada na/pela reflexão sobre a prática, caracterizada por um movimento de ação-reflexão-ação, que caminha para um menor distanciamento entre a teoria e a prática. Entende-se, nesse sentido, que -entre uma determinada teoria assumida (ou que se pretende assumir) - e a prática (que se supõe ressignificada)- existe a teoria do sujeito, a qual se constrói a partir das indagações daquilo que ele, como "sujeito reflexivo", faz.

Considerando esses questionamentos, o sujeito poderá despertar sua consciência crítica, questionando o conhecimento e a si próprio.

A pesquisa, que será agora descrita, ocorreu no âmbito da formação inicial de professores de Física de uma Universidade Pública e procurou acompanhar o desempenho de licenciandos (quando esses cursaram uma das disciplinas, considerada essencial na formação inicial de professores), a Prática de Ensino.

Essa disciplina foi planejada pelo docente responsável, segundo um processo educativo sistematizado, balizado a partir do diálogo, em que se privilegiou a reflexão sobre a ação. Durante as atividades de estágio de regência e as atividades de ensino, foram organizadas ações a partir de referenciais teóricos derivados da pesquisa em Educação; mais especificamente, da pesquisa em Ensino de Física.
A pesquisa procurou avaliar, ao final do processo, que marcas lingüísticas (em relação aos referenciais teóricos, trabalhados pelo docente), foram deixadas nos enunciados dos relatórios, apresentados pelos professores, comprobatórias que essas teorias foram incorporados à prática de ensino desses futuros professores, durante as atividades desenvolvidas ao longo do processo de regência.

Para tanto, a pesquisa centrou-se em: 1) analisar o discurso dos licenciandos, através da interpretação de marcas lingüísticas que foram expressas (implícita e explicitamente) em seus relatórios. Por meio desses relatos, foram descritas suas práticas pedagógicas, desenvolvidas durante os estágios de regência; 2) verificar, através desses discursos, o grau de apropriação de alguns pontos que identificam os referenciais teóricos sugeridos pelo professor de Prática de Ensino na preparação para esse estágio supervisionado; 3) gerar subsídios que possam contribuir para a discussão sobre a formação inicial de professores de Física.

Para a análise dos dados obtidos, ou seja, para interpretar os discursos dos licenciandos exibidos em seus relatórios, utilizou-se como referência os estudos de Orlandi $(1996,2001,2002)$ que empregam conceitos como "formação ideológica" e "formação discursiva" e derivam dos estudos de análise de discurso na linha francesa, principalmente aqueles desenvolvidos por Pêcheux (1990; 1994).

Apresenta-se, a seguir, como exemplo desta análise, a interpretação de parte dos dados recolhidos: apenas aqueles 
relacionados à análise do discurso de um dos licenciandos, que denominamos pela sigla LHA.

\section{A análise do discurso como referencial para leitura de dados}

Para Orlandi (2001), nos discursos dos sujeitos, a materialidade ideológica se concretiza, sendo uma das instâncias em que se funda o aspecto da "existência material" da ideologia expressa no discurso. Nesse sentido, não há discursos científicos que sejam neutros, todos portam uma determinada visão impregnada de ideários. Analisando-se a articulação da ideologia com o discurso, dois conceitos em Análise do Discurso (AD) devem ser mencionados: o de "formação ideológica" (FI) e o de "formação discursiva" (FD).

Os critérios para a caracterização de um determinado discurso são baseados no referente e nos participantes do discurso, ou seja, o objeto do discurso e seus interlocutores. Considera-se que há dois processos: o parafrástico e o polissêmico, que são constitutivos da tensão que produz o texto (Orlandi, 2001). A polissemia representa a tensão estabelecida pela relação homem/mundo, pela intromissão da prática e do referente na linguagem. Nesse sentido, caracterizamse os três tipos de discurso: o discurso lúdico - como aquele em que o seu objeto se mantém presente, enquanto tal e os interlocutores se expõem a essa presença, resultando o que chama de polissemia aberta; o discurso polêmico: que mantém a presença do seu objeto, os participantes não se expõem, mas procuram dominar o seu referente, indicando particularidades pelas quais se 0 olha e se o diz - trata-se de uma polissemia controlada; e o discurso autoritário, no qual o referente está ausente, oculto pelo dizer, não há interlocutores, mas um agente exclusivo; trata-se de uma polissemia contida (o exagero é a ordem no sentido) em que se diz: isso é uma ordem, é assim que se faz e não de outro jeito. Nesse discurso, o sujeito passa a ser um instrumento de comando. Esse discurso recusa outra forma de ser, que não a linguagem autoritária de especialistas, baseia-se, portanto, no "já dito" e tido como o único certo e possível.

O discurso pedagógico que se apresenta com fins de se ensinar e/ou expor idéia ou convicção insere-se entre os discursos do tipo autoritário, e é caracterizado por Orlandi enquanto tal. A estratégia básica deste deveria ser a pergunta pelo referente $(R)$, isto é, o objeto do discurso, que, no discurso pedagógico, aparece como algo que se "deve" saber.

No entanto, percebe-se que a estratégia adquire, no discurso pedagógico, a forma imperativa de se dizer o previsível. Entende-se que, para interpretar um determinado discurso, dentre os diversos existentes na sociedade, é preciso considerar as diferentes formações discursivas, assim como, as formações ideológicas que lhes dão origem. Do mesmo modo, é necessário compreender que este discurso pode ser interpretado de diversas maneiras. 


\section{A pesquisa}

A pesquisa - que aqui relatamos - foi desenvolvida junto a uma amostra de 22 alunos de um curso de licenciatura em Física de uma universidade pública paulista e procurou acompanhar o desempenho desses licenciandos, quando cursaram a disciplina de Prática de Ensino de Física, ministrada em dois semestres consecutivos, durante o ano de 2001, num total de cerca de 150 horas de atividades.

No primeiro semestre, o docente responsável pela disciplina, privilegiou o levantamento de temas de interesse dos graduandos, que se transformaram em objetos de estudo, visando embasálos para o planejamento das atividades de ensino, ministradas a uma turma de alunos do Ensino Médio, durante o estágio de regência, realizado no segundo semestre. Foram levantados os seguintes temas: 1) Por que ensinar Física em países subdesenvolvidos? 2) O que deve saber e saber fazer o professor de Física do Ensino Médio? 3) Existem conteúdos a serem privilegiados? Quais? 4) Como construir o conhecimento numa concepção dialógico-problematizadora? Para a problematização desses temas, o docente sugeriu o estudo dos seguintes artigos: Por que ensinar Física em países subdesenvolvidos? (Gonzalez, 1976); ¿Que hemos de saber y saber hacer los profesores de ciencias? (Gil Perez, 1991); A Proposta Curricular para o ensino de Física para $\circ 2^{\circ}$ grau da Coordenadoria de Estudos e Normas Pedagógicas (CENP) da Secretaria de Estado da Educação do Estado de São Paulo (São Paulo, 1992);
Concepção Bancária x Concepção problematizadora: a concepção bancária da educação como instrumento da opressão - seus pressupostos, sua crítica (Freire, 1987); Reflexões sobre o ensino de Física no Brasil: práticas, conteúdos e pressupostos (Villani, 1984).

Paralelamente aos estudos de reflexão sobre os textos acima, os licenciandos foram divididos em cinco grupos, com a finalidade de estudar conteúdos de Física (Mecânica, Termologia, Óptica, Eletricidade e Magnetismo e Física Moderna e Contemporânea) que poderiam ser abordados em situações de sala de aula, durante as atividades do estágio de regência no Ensino Médio. Das atividades da disciplina Prática de Ensino, ainda neste primeiro semestre, constava o estágio de observação, realizado junto a escolas da região, no qual foram observados aspectos ligados à estrutura organizacional das escolas selecionadas, tais como: seus aspectos físicos; suas propostas pedagógicas; a organização escolar; os mecanismos de ação coletiva interna; as horas de trabalho pedagógico do corpo docente; o papel do ensino da Física, enquanto componente curricular, e a constituição do núcleo de direção da escola.

Todas as atividades realizadas na disciplina nesse primeiro semestre foram registradas em um diário pelo pesquisador; algumas delas foram filmadas, com o consentimento do docente e dos licenciandos.

No segundo semestre, baseados nas atividades realizadas anteriormente, os licenciandos planejaram e ofereceram aos 
alunos do Ensino Médio de um colégio público da região um curso de 68 horas de atividades, constituído de módulos sobre as diversas partes da Física, essas normalmente presentes no currículo do Ensino Médio: Mecânica, Termologia, Óptica, Eletricidade e Magnetismo e Noções de Física Moderna e Contemporânea.

O curso foi denominado "O outro lado da Física" e tinha por meta proporcionar aos alunos do Ensino Médio, bem como aos licenciandos, uma visão alternativa de aprendizagem, centrada numa abordagem dialógica, na problematização dos conteúdos e respeitando estudos derivados da pesquisa em Ensino de Física, tais como: a preocupação com a inserção da História e Filosofia da Ciência no ensino, o respeito às concepções prévias (espontâneas ou alternativas) dos alunos no planejamento e desenvolvimento das atividades de ensino, a inserção de tópicos de Física Moderna e o favorecimento de discussões sobre as relações entre Ciência, Tecnologia, Sociedade e o cotidiano dos alunos.

No final do curso, denominado pelos licenciandos de "O outro lado da Física", foi solicitado aos licenciandos que preenchessem o relatório de regência, individualmente, relatando em forma de diário a seqüência de aulas ministradas pelo seu grupo no Ensino Médio. Todas as aulas deste curso foram registradas em vídeos, coletando-se material para análise/reflexão em encontros com todos os licenciandos. Esses encontros foram realizados quinzenalmente durante todo o processo, após a conclusão de cada um dos módulos lecionados, visando à reflexão sobre suas práticas, segundo os referenciais teóricos propostos pelo docente da referida disciplina, os quais, conforme anteriormente relatado, já haviam sido discutidos no semestre anterior.

\section{Os dados recolhidos}

A descrição das etapas da pesquisa mostra que o processo todo gerou uma significativa quantidade de dados. Na presente comunicação, serão apresentados apenas aqueles relativos ao discurso presente no relatório de um dos licenciandos, no qual estão descritas as aulas ministradas por seu grupo durante o estágio realizado, numa escola de nível médio, sobre eletricidade.

Este relatório foi escolhido devido sua riqueza de informações. Procurou-se interpretar as marcas de apropriação dos referenciais teóricos, no discurso (contido no relatório) do professor de Prática de Ensino de Física pelos licenciandos. Em outras palavras, analisar o impacto dos referenciais estudados na disciplina de Prática de Ensino, previamente à experiência dos licenciandos na sala de aula no Ensino Médio.

Procurando tornar mais clara a identificação das possíveis marcas existentes nos relatos dos licenciandos, optamos por analisar o relatório deste licenciando, segundo os seguintes grandes temas: Concepções Espontâneas e/ou Alternativas em Física (CE), História e Filosofia da Ciência (HFC), Ciência Tecnologia e Sociedade (CTS), Abordagem Dialógica (AD) x Abordagem Tradicional (AT).

Numeramos todas as linhas do relato, 
para facilitar a localização dos excertos selecionados para análise. $\mathrm{O}$ relato é original; portanto, a linguagem do licenciando, os possíveis erros de ortografia, de gramática, bem como de digitação foram mantidos, preservando, dessa maneira, a autenticidade do mesmo.
Na seqüência, mostrarmos a interpretação do relatório do licenciando denominado, na pesquisa, de LHA. Trata-se, portanto, do relatório específico sobre as aulas do módulo de Eletricidade e Magnetismo, desenvolvidas durante o Curso "O outro lado da Física".

\section{Licenciando LHA}

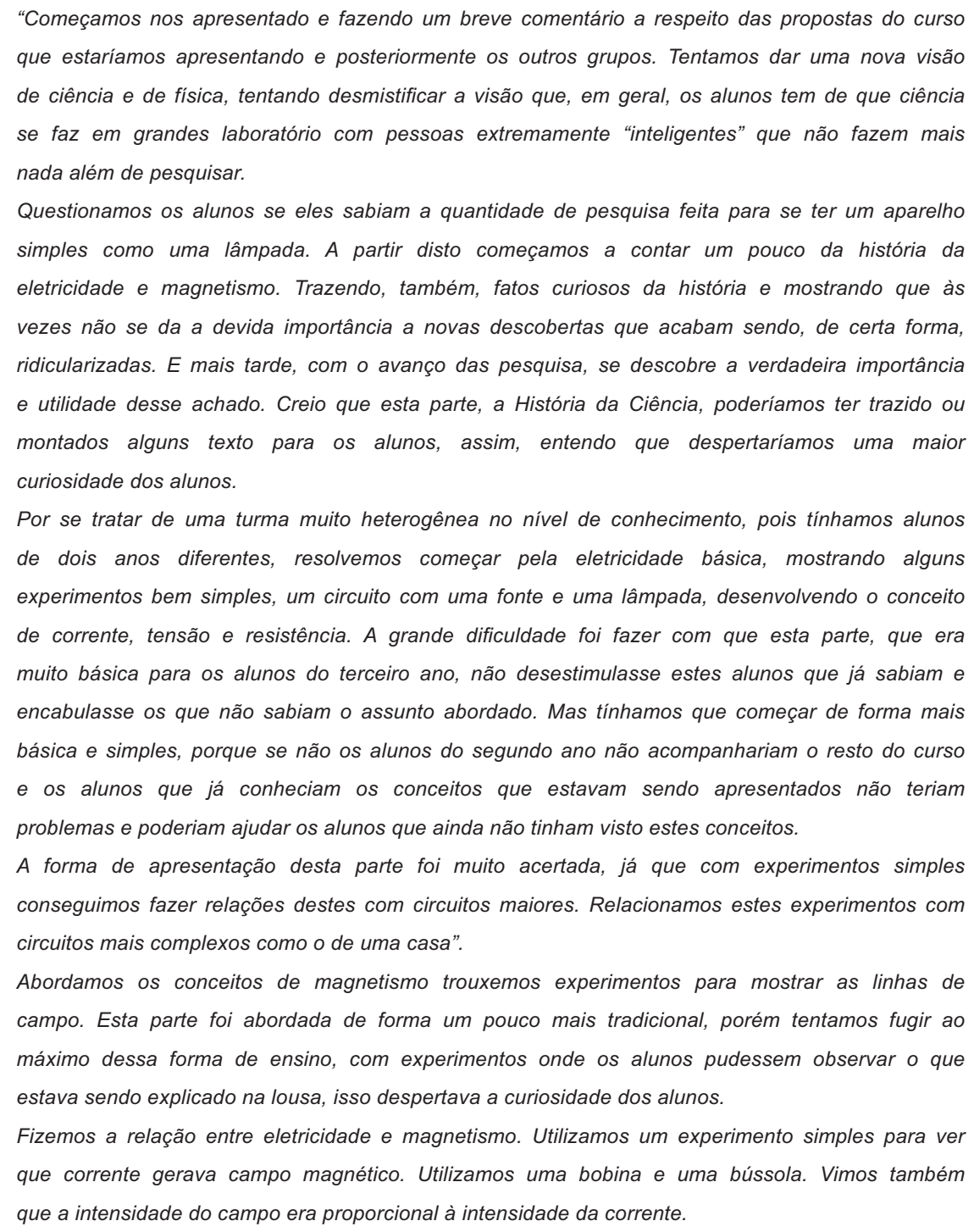



elétrica geradora de campo magnético, perguntamos se o inverso seria possível, ou seja, campo magnético poderia gerar corrente elétrica. Mostramos outro experimento bem simples movimentar um imã na frente de uma bobina e verificar o que acontecia com o marcador de um amperímetro (aparelho que mede corrente elétrica). Os alunos observaram que o marcador oscilava quando o imã se movia e parava quando o imã parava. Assim, os alunos puderam ver que essa relação entre eletricidade e magnetismo era uma relação importante, pois quase toda energia que consumimos e gerada dessa forma e que em uma usina hidrelétrica o que acontece é exatamente o que acabamos de ver, um imã se movimentando dentro de uma bobina, e que faz esse o papel do braço, para que haja esse movimento é a água, no caso da hidrelétrica, o vent no caso das usinas eólicas, o gás nas termelétricas e assim por diante.

Mostramos alguns dispositivos eletrônicos, explicamos os sistemas de cores para dar os valores nominais dos resistores, mostramos o funcionamento de um diodo e de transistores. Bem como suas aplicações.

Trouxemos algumas respostas para perguntas que os alunos fizeram a respeito das linhas de transmissão. Os alunos leram em alguma revista que as perdas de energia nas linhas de transmissão poderiam se minimizadas se esses cabos fossem substituídos por outros, onde resistência fosse menor. Chegamos a conclusão, após discutirmos os aspectos favoráveis e desfavoráveis dessa possível troca, que não seria viável, pois os custos com torres seria bem maior do que a economia de energia.

Levantamos algumas questões de caráter social a respeito da falta de energia elétrica e possiveis soluções desse problema. Questões como as perdas nas linhas de transmissão por falta de manutenção, os "gatos" feitos nas favelas porque o pessoal não tem como pagar, a falta e investimento que ocorreu nos últimos anos porque o governo estava privatizando o sistema de produção de energia, as medidas tomadas pelo governo são ou não a solução para o problema. Com esta discussão queríamos chamar a atenção dos alunos para uma questão mais ampla de que nós temos que ser mais responsáveis e críticos questionando porque a situação está dessa forma, será que podemos fazer algo para mudar e melhorar, não só na questão da energia, mas em todos os aspectos, educação, saúde, etc".

"Entramos em motores e geradores, essa parte não teve como fugir de uma explicação mais formal, mas também levamos experimentos para demonstração e fazer com que os alunos observasse e verificassem se o que foi explicado se confirma, passamos um pequeno gerador conectado a um led onde os alunos podiam girar uma das extremidades e ver que o led acendia verificando que o movimento gerava corrente elétrica, que é o mesmo princípio da hidrelétrica. Um colega aluno da Pós-Graduação que estava assistindo nossa aula sugeriu a idéia de abrir o gerador para que os alunos observassem como estava montado o circuito, assim os alunos compreenderam melhor o funcionamento do equipamento.

Explicamos que o funcionamento de motor é o contrario de um gerador, ou seja, o gerador usa o movimento e gera energia e o motor faz o contrario usa energia e gera movimento. Também ilustramos esta explicação com um experimento, um motorzinho e uma bateria, ligando-se a bateria ao motor ele girava a outra extremidade.

74 Com os dois experimentos circulando entre os alunos observamos que eles faziam outras 
75 verificações, como o aumento da intensidade da corrente com o aumento da velocidade com que

76 se girava a extremidade do gerador. Eles fizeram com que a extremidade do gerador fosse 77 movimentada pelo motor. Verificaram que se ligando a bateria nas extremidades do led no 78 gerador deveria se transformar em um motor, o que realmente aconteceu, verificando que o 79 funcionamento de um motor é o contrario de um gerador.

80 Encerramos fazendo uma discussão de como eles viram o desenvolvimento desta parte do curso,

81 se eles gostaram, se foi o que eles esperavam, perguntamos das falhas e sugestões para os 82 outros grupos. Segundo eles o curso foi muito bom, bem ilustrativo e pratico que o principal 83 problema foi o tempo muito curto

Quadro I - licenciando LHA

\begin{tabular}{|c|c|c|}
\hline Marcas* & Segmentos escolhidos/Discurso & $\begin{array}{l}\text { Linhas } \\
\qquad\left(\mathbf{N}^{\circ}\right)\end{array}$ \\
\hline CE & - & - \\
\hline \multirow[b]{2}{*}{ HFC } & $\begin{array}{l}\text { "...começamos a contar um pouco da história da eletricidade e mag- } \\
\text { netismo [...]...fatos curiosos da história". }\end{array}$ & $7-8$ \\
\hline & $\begin{array}{l}\text { "Creio que esta parte, a História da Ciência, poderíamos ter trazido ou } \\
\text { montados alguns texto para os alunos, assim, entendo que desperta- } \\
\text { ríamos uma maior curiosidade dos alunos". }\end{array}$ & $11-13$ \\
\hline CTS & - & - \\
\hline \multirow{6}{*}{ AD/AT } & $\begin{array}{l}\text { "Começamos o curso fazendo um breve comentário a respeito das } \\
\text { propostas do curso que estaríamos apresentando". }\end{array}$ & $1-2$ \\
\hline & $\begin{array}{l}\text { "Tentamos dar uma nova visão de ciência e de física, tentando des- } \\
\text { mistificar a visão que, em geral, os alunos tem de que ciência se faz } \\
\text { em grandes laboratório". }\end{array}$ & $2-4$ \\
\hline & $\begin{array}{l}\text { "Questionamos os alunos se eles sabiam a quantidade de pesquisa } \\
\text { feita para se ter um aparelho simples como uma lâmpada". }\end{array}$ & $6-7$ \\
\hline & $\begin{array}{l}\text { “...tínhamos que começar de forma mais básica e simples, porque se } \\
\text { não os alunos do segundo ano não acompanhariam o resto do curso } \\
{[\ldots] \text {...os alunos que já conheciam os conceitos[...]...poderiam ajudar os }} \\
\text { alunos que ainda não tinham visto. [...]A forma de apresentação desta } \\
\text { parte foi muito acertada, já que com experimentos simples consegui- } \\
\text { mos fazer relações destes com circuitos maiores" }\end{array}$ & $19-24$ \\
\hline & $\begin{array}{l}\text { “...os conceitos de magnetismo... [...]... foi abordada de forma um } \\
\text { pouco mais tradicional, porém tentamos fugir ao máximo dessa forma } \\
\text { de ensino, com experimentos onde os alunos pudessem observar o } \\
\text { que estava sendo explicado na lousa...". }\end{array}$ & $26-29$ \\
\hline & $\begin{array}{l}\text { "Fizemos a relação entre eletricidade e magnetismo... [...] Utilizamos } \\
\text { experimento simples para ver que corrente gerava campo magnético. } \\
\text { [...] uma bobina e uma bússola". }\end{array}$ & $30-31$ \\
\hline
\end{tabular}

Continúa... 


\begin{tabular}{|c|c|c|}
\hline \multirow{7}{*}{ AD/AT } & $\begin{array}{l}\text { "Mostramos outro experimento bem simples, movimentar um imã na } \\
\text { frente de uma bobina e verificar o que acontecia com o marcador de } \\
\text { um amperímetro". }\end{array}$ & $35-37$ \\
\hline & $\begin{array}{l}\text { "... os alunos puderam ver que essa relação entre eletricidade e mag- } \\
\text { netismo era uma relação importante". }\end{array}$ & 38-39 \\
\hline & $\begin{array}{l}\text { "Os alunos leram em alguma revista que as perdas de energia nas } \\
\text { linhas de transmissão poderiam se minimizadas se esses cabos fos- } \\
\text { sem substituídos por outros, onde a resistência fosse menor. [...] a } \\
\text { conclusão, após discutirmos os aspectos favoráveis e desfavoráveis } \\
\text { [...]...pois os custos com torres seria bem maior do que a economia } \\
\text { de energia". }\end{array}$ & $48-52$ \\
\hline & $\begin{array}{l}\text { "Levantamos algumas questões de caráter social a respeito da falta de } \\
\text { energia elétrica e possíveis soluções desse problema. [...] os "gatos" } \\
\text { feitos nas favelas porque o pessoal não tem como pagar". }\end{array}$ & $53-55$ \\
\hline & $\begin{array}{l}\text { “...queríamos chamar a atenção dos alunos para uma questão mais } \\
\text { ampla de que nós temos que ser mais responsáveis e críticos”. }\end{array}$ & $58-59$ \\
\hline & $\begin{array}{l}\text { "Entramos em motores e geradores, essa parte não teve como fugir } \\
\text { de uma explicação mais formal [...]... levamos experimentos para de- } \\
\text { monstração e fazer com que os alunos observasse e verificassem se } \\
\text { o que foi explicado se confirma". }\end{array}$ & $62-64$ \\
\hline & $\begin{array}{l}\text { "Encerramos fazendo uma discussão }[\ldots] \ldots \text { se eles gostaram, se foi o } \\
\text { que eles esperavam }[\ldots] \ldots \text { Segundo eles o curso foi muito bom }[\ldots] \ldots \text { o } \\
\text { principal problema foi o tempo muito curto". }\end{array}$ & $80-83$ \\
\hline
\end{tabular}

* CE= Concepção Espontânea; HFC = História e Filosofia da Ciência; CTS = Ciência Tecnologia e Sociedade; $A D$ = Abordagem Dialógica; $A T=$ Abordagem Tradicional.

\section{Análise dos segmentos escolhidos no relato do licenciando LHA}

\section{HFC}

Quando LHA afirma no trecho (8) que: “... começamos a contar um pouco da história da eletricidade e magnetismo [...]... fatos curiosos da história" ele está tentando mostrar para os alunos a importância da História da Ciência (Carvalho E Castro, 1992; Solbes E Traver, 1996), mais adiante no trecho (12-13) "Creio que esta parte, a História da Ciência, poderíamos ter trazido ou montado alguns textos para os alunos, assim, entendo que despertaríamos uma maior curiosidade dos alunos".

Percebe-se pelas marcas da enunciação no enunciado: “... poderíamos ter trazido ou montad o alguns textos para os alunos...", que, o grupo não conseguiu, a princípio, motivar os alunos pela forma que expuseram o conteúdo que estavam tratando. A locução verbal utilizada pelo enunciador expõe a sua intenção de transmitir a importância da História da Ciência (Carvalho E Castro, 1992; Solbes E Traver, 1996), bem como a escolha do adjetivo "curiosos" reforça esta intenção. 
Revela, entretanto uma abordagem ou opção para o uso de HC no Ensino: abordar pontos curiosos, ou seja, usar a $\mathrm{HC}$ como condicional ou uma estratégia de motivar os alunos. Por outro lado, o LHA percebe que deveriam ter preparado material sobre a História da Ciência. Esta intenção está clara pelo emprego do verbo poder no futuro do pretérito: "poderíamos ter trazido".

Um fato significante é que LHA parece ter compreendido a importância da História da Ciência no ensino: "despertaríamos uma maior curiosidade". Fica explícito que o enunciador crê que despertou curiosidade (motivou os alunos), mas que esta poderia ser mais intensa: "uma maior". Este fato neutraliza a posição inicial do enunciador quando, no início de seu discurso, relata apenas que estava tentando.

\section{$A D / A T$}

Podemos verificar através do discurso do licenciando no trecho selecionado (1-2): "Começamos nos apresentando e fazendo um breve comentário a respeito das propostas do curso que estaríamos apresentando" que o licenciando/grupo não se preocupou em verificar a opinião dos alunos do Ensino Médio sobre as propostas de ensino que foram planejadas, isto fica evidente pelas marcas da enunciação deixadas no enunciado: "Começamos nos apresentado e fazendo um breve comentário a respeito das propostas do curso". Fica explícita que a intenção do enunciador (es) não é saber sobre quais propostas os alunos gostariam de discutir.
O uso do adjetivo "breve" (comentário) implicitamente sugere e reforça aos enunciatários (alunos) que estas propostas já estavam elaboradas e até sintetizadas. Pela forma como LHA começa seu discurso "fazendo um breve comentário" e não deixando espaço para que os alunos colocassem suas propostas, fica implícita a intenção do grupo: não considerar intervenções dos enunciatários. Deste modo, não foi privilegiada uma abordagem dialógica. Pelo contrário, as marcas da enunciação deixadas no enunciado, como se pode ver a seguir, mostram que o modelo de ensino proposto pelo enunciador do relatório mais se aproxima do paradigma da racionalidade técnica (Schön, 1992; Garcia, 1992; Gomez, 1992; Abib, 1996).

Em (3-4) o licenciando assegura o seguinte: "Tentamos dar uma nova visão de ciência e de física, tentando desmistificar a visão que, em geral, os alunos tem de que ciência se faz em grandes laboratórios". Nessa afirmação, o enunciador está utilizando-se, em parte, do discurso defendido nos referenciais estudados na disciplina de Prática de Ensino de Física (VI/VII), quanto à organização do conteúdo programático, não consideraram os alunos (enunciatários do discurso relatado): "Tentamos dar". Comprova-se que a intenção implícita do enunciador é transmitir algo já pronto: nós vamos dar e vocês vão receber. Fica evidente a utilização de uma concepção bancária da educação (Freire, 1987). Desprezaram também as concepções espontâneas dos alunos. Não houve uma verificação se os alunos aos quais estavam ministrando a 
aula realmente tinham uma visão própria da ciência.

No excerto (6-7) "Questionamos os alunos se eles sabiam a quantidade de pesquisa feita para se ter um aparelho simples como uma lâmpada". Pelo uso do verbo questionar, usado na expressão: "questionamos os alunos..." percebe-se a intenção do grupo: tentar discutir com os alunos a propósito da produção de um aparelho tecnológico, isso reflete de maneira implícita a questão da problematização do conteúdo discutido na disciplina de Prática de Ensino de Física (VI/VII) quando do estudo do texto de Paulo Freire. Mas esta intenção fica apenas no plano superficial discursivo, já que não se sabe se os professores (enunciadores do relatório) também deram voz aos alunos para que estes também pudessem questionar.

No trecho (20-25), o enunciador argumenta que, pelo fato dos alunos originarem-se de séries diferentes, eles teriam problemas para acompanhar o conteúdo e optam por começar do principio. “... tínhamos que começar de forma mais básica e simples, porque se não os alunos do segundo ano não acompanhariam o resto do curso" na seqüência, afirmam que os enunciatários (alunos do terceiro ano) poderiam auxiliá-los com os alunos do segundo ano, porque esses ainda não tinham visto os conceitos de eletricidade.

“... os alunos que já conheciam os conceitos [...]... poderiam ajudar os alunos que ainda não tinham visto".

Em seguida afirmam: "A forma de apresentação desta parte foi muito acertada, já que com experimentos simples conse- guimos fazer relações destes com circuitos maiores". ". As marcas da enunciação deixadas nesse enunciado (20-25) podem ser interpretadas de várias maneiras; por um lado, o grupo poderia ter a intenção de estar realmente preocupado com os alunos do segundo ano: “... tínhamos que começar de forma mais básica e simples". ". O uso dos adjetivos "básica" e "simples", comprovam esta intencionalidade. Essa intencionalidade é reforçada, quando os enunciadores/professores optaram por iniciar com a eletricidade básica e com experimentos simples: "com experimentos simples conseguimos fazer relações destes com circuitos maiores". Por outro lado, quando empregam o verbo "poder" -no futuro do pretérito indicativo- afirmando que os alunos do terceiro ano poderiam ajudá-los com os alunos do segundo ano, uma vez que, estes já tinham estudado os conceitos que o grupo trabalharia, não pode ser descartada a hipótese de que também eles estivessem inseguros, em decorrência dos alunos do terceiro ano dominarem (ou não) o conteúdo. O que poderia estar incomodando o grupo, pois possibilitaria aos alunos do terceiro ano questioná-los, caso houvesse uma interpretação errônea dos conceitos. No entanto, o convite para que os auxiliassem com os alunos do segundo ano, pode ter sido uma estratégia, já que, desta maneira, o grupo também estaria colocando estes alunos no papel de professores. O receio de que os alunos tivessem mais conhecimento (do que eles próprios) pode ter preocupado, uma vez que, habituaram-se a sempre ver o professor como o "dono do saber" (Charlot, 
1986; Bejarano, 2001; Villani, 1981; Freire, 1987).

No excerto (27-30), “... os conceitos de magnetismo... [...]... foi abordada de forma um pouco mais tradicional, porém tentamos fugir ao máximo dessa forma de ensino, com experimentos onde os alunos pudessem observar o que estava sendo explicado na lousa..."; é possível notar, por meio das marcas da enunciação "de forma um pouco mais tradicional", que os enunciadores/professores apesar de terem exposto a aula de maneira tradicional, preocupavam-se em ministrá-las de forma não-tradicional; percebendo o equívoco, procuram se justificar: "... tentamos fugir ao máximo dessa forma de ensino...". Provavelmente essa "tentativa de fuga" do modelo tradicional, enfatizada neste segmento seja resultado das discussões dos textos realizados na disciplina de Prática de Ensino de Física (VI/VII), os quais, em sua maioria, defendiam uma concepção construtivista do conhecimento. Por outro lado, estes poderiam estar lutando para não serem "tradicionais".

Nos trechos a seguir, é possível inferir que os enunciadores estão procurando fazer a relação entre a eletricidade e o magnetismo, utilizando-se sistematicamente não somente das equações, mas de experimentos para demonstrar suas afirmações: (32-34) "Fizemos a relação entre eletricidade e magnetismo... [...] Utilizamos experimento simples para ver que corrente gerava campo magnético. [...]... uma bobina e uma bússola”. ; (3840) "Mostramos outro experimento bem simples, movimentar um imã na frente de uma bobina e verificar o que acontecia com o marcador de um amperímetro". ; (42-44) "... os alunos puderam ver que essa relação entre eletricidade e magnetismo era uma relação importante"; (68-70) "Entramos em motores e geradores, essa parte não teve como fugir de uma explicação mais formal [...]... levamos experimentos para demonstração e fazer com que os alunos observasse e verificassem se o que foi explicado se confirma".

É notável que os enunciadores/professores estivessem buscando ministrar a aula de acordo com os referenciais teóricos trabalhados anteriormente, uma vez que, esses versavam sobre a relação entre a teoria e a prática, defendendo a idéia de que não deveria haver uma dicotomia entre ambas (Freire, 1987; Schön, 1992; Abib, 1996; Carvalho, 2001), sendo fundamental a existência de uma ligação entre os conhecimentos veiculados pelos pesquisadores, os problemas práticos presentes no cotidiano dos alunos e vivenciados pelo professor em sala de aula. Pode-se verificar, no entanto, através das marcas da enunciação: "essa parte não teve como fugir de uma explicação mais formal" que os professores/enunciadores tinham a intencionalidade de fazer a relação entre a eletricidade e o magnetismo (procurando mostrar aos alunos sua importância), mas trabalharam essa relação de maneira tradicional e se justificam: "não teve como fugir".

Ou seja, na verdade explicaram o fenômeno para os alunos do Ensino Médio e depois fizeram uma demonstração 
experimental para comprovar o que tinham exposto na teoria, como pode ser percebido pelas marcas da enunciação neste enunciado: "levamos experimentos para demonstração para fazer com que os alunos observassem e verificassem se o que foi explicado se confirma". ". O uso do verbo "fazer com" mostra realmente um empenho sincero do enunciador desse relato em tornar o conteúdo mais significativo, mas também fica explícita a falta de compreensão que esse tem sobre o que é observar, uma vez que podemos enfatizar/motivar alunos para despertaIhe 0 interesse pela observação, mas não podemos "fazer com" que esta ação seja garantida. De maneira geral, é essa metodologia que os enunciadores presenciaram (obtiveram) durante grande parte de sua formação, tanto no Ensino Médio quanto nas disciplinas específicas de Física na Universidade. Estão, na realidade, reproduzindo o modelo utilizado pelos docentes do ensino superior, quando do período de formação.

Nos enunciados (68-70), assim como anteriormente, em (27-30), os enunciadores também buscam justificar-se, ao perceber que o trabalho que estão executando situa-se dentro de uma concepção de ensino, baseada na racionalidade técnica (Garcia, 1992; Gomez, 1992, Schön, 1992, 2000; Abib, 1996).

Pode-se notar neste trecho (53-55) por meio das marcas da enunciação (após discutirmos os aspectos favoráveis e desfavoráveis) que os enunciadores tinham explicitamente a intenção de debater as perguntas feitas pelos alunos do Ensino
Médio de forma que a discussão envolvesse os participantes, ou seja, estavam procurando problematizar o tema (Gil Perez, 1991; Freire, 1987), conforme segue: "Os alunos leram em alguma revista que as perdas de energia nas linhas de transmissão poderiam ser minimizadas se esses cabos fossem substituídos por outros, onde a resistência fosse menor. [...]... a conclusão, após discutirmos os aspectos favoráveis e desfavoráveis... [...]... pois os custos com torres seriam bem maior do que a economia de energia". É possível perceber que os enunciadores propiciaram uma certa abertura para os alunos do Ensino Médio, isso fica claro, quando aceitaram discutir o tema abordado pela revista que os alunos leram: "as perdas de energia nas linhas de transmissão". Nota-se que debateram o tema com os alunos: isso é mais uma marca das discussões perpetradas entre os enunciadores e o professor de Prática de Ensino de Física.

Outros enunciados que nos dão indícios das marcas da enunciação no discurso do professor de Prática de Ensino no relato do LHA é quando afirma (58-59) que: "Levantamos algumas questões de caráter social a respeito da falta de energia elétrica e possíveis soluções desse problema. [...] os "gatos" feitos nas favelas porque o pessoal não tem como pagar". (64-65) “... queríamos chamar a atenção dos alunos para uma questão mais ampla de que nós temos que ser mais responsáveis e críticos". Segundo o relato do LHA, o grupo tentou problematizar (Gil Perez, 1991; Freire, 1987) a questão com os alunos do Ensino Médio, chaman- 
do atenção para a reflexão em torno das questões socioeconômicas da demanda e produção de energia elétrica em nosso país. A utilização da problematização fica evidente quando o enunciador utiliza o verbo "levantar" no presente do indicativo afirmando: "Levantamos algumas questões de caráter social a respeito da falta de energia elétrica e as possíveis soluções desse problema". Na seqüência, o enunciador explica algumas das questões sociais geradas com a problematização em torno da falta de energia. Uma delas foi à discussão sobre: "os gatos feitos nas favelas" esta forma de instalação elétrica é construída pela população carente que não possui uma renda suficiente para pagar pela energia que consome, sendo esta a única maneira que encontram para terem acesso à rede de energia elétrica.

No enunciado seguinte, o uso do verbo "querer", no futuro do pretérito, marca as intenções dos enunciadores quando da utilização das problematizações; mas, ao mesmo tempo, não garante que o objetivo foi alcançado; apenas realça intencionalidade: "queríamos chamar a atenção dos alunos para uma questão mais ampla de que nós temos que ser mais responsáveis e críticos".

Provavelmente o grupo tenha colocado em pauta este assunto devido à crise de energia (chamada popularmente de "Apagão") ocorrida no ano de 2001, quando o Brasil passou por uma escassez gravíssima, que determinou oito meses de racionamento para a população, que ainda se mantém em situação de alerta.
No trecho (89-92) LHA faz referência ao término das aulas do grupo de eletricidade. "Encerramos fazendo uma discussão [...]... se eles gostaram, se foi o que eles esperavam [...]... Segundo eles o curso foi muito bom [...]... o principal problema foi o tempo muito curto". As perguntas feitas pelo grupo para os alunos, sobre os temas abordados, refletem suas dúvidas e preocupações, pelo uso da conjunção subordinativa adverbial (condicional) se. Estavam preocupados em ministrar suas aulas de maneira que os alunos "gostassem" para obter a aprovação desses, e a do professor da Prática de Ensino, que os avaliaria no final do semestre. Uma prova disso é que argumentaram enfaticamente que o curso foi muito bom, utilizando-se do apoio dos alunos. A preocupação do grupo ratifica os resultados de várias pesquisas (Fuller, 1969; Kagan, 1992; Beach \& Person, 1998; Bejarano, 2001) que afirmam a existência de um conjunto de preocupações com as quais os professores se deparam no inicio de sua carreira docente.

\section{Conclusões}

É possível perceber através da análise do discurso presente no relatório elaborado pelo licenciando LHA que, muito embora os enunciadores dos discursos analisados (grupo de eletricidade e magnetismo), tenham buscado articular suas ações pedagógicas dentro de uma concepção de ensino alternativa, o discurso do licenciando analisado, bem como da maioria dos demais, aproxima-se do discurso pedagógico autoritário que é característico da racionalidade 
técnica. No entanto percebe-se também, que já aparecem no relatório indícios do discurso polêmico. É importante salientar que, embora o objetivo da pesquisa fosse analisar a apropriação do discurso do docente de Prática de Ensino de Física pelos licenciandos, através dos referenciais teóricos discutidos anteriormente (refletidos nos relatórios de estágio de regência), a

\section{ReferÊnCIAs BiblográficAs}

Aragão, R. M. R. (2000). Uma Interação Fundamental de Ensino e de Aprendizagem: professor, aluno, conhecimento...In: Schnetzler, R. P., e Aragão, R.M.R (Orgs.). En Ensino de Ciências: fundamentos e abordagens. Campinas: R. Vieira Gráfica e Editora, pp. 82-98.

Abib, M. L. V. S. (1996). Em busca de uma nova formação de professores. En Ciência \& Educação, Bauru, V. 3, pp. 60-72.

Bejarano, N. R. R. (2001). Tornando-se professores de física: conflitos e preocupações na formação inicial. 300f, Universidade de São Paulo, Faculdade de Educação, Tese (Doutorado em Educação), São Paulo.

Bogdan, R., y Biklen, S. (1994). Investigação qualitativa em Educação: uma introdução à teoria e aos métodos. Porto: Porto Editora.

Brandão, H. H. N. (1997). Introdução à Análise do Discurso. $6^{a}$ ed. Campinas: Editora da Unicamp.

Carvalho, A. M. P, y Gil Pérez, D. (2001). O. saber e o saber fazer dos professores. In: Castro, A.d. E Carvalho, A. M. P. (Orgs.). En Ensinar a Ensinar: Didática para a Escola Fundamental e Média. São Paulo: Pioneira Thomson Learning, pp. 107-124. atuação desses futuros docentes também é fortemente marcada pelas outras disciplinas ministradas pelos demais membros do corpo docente do Curso de Licenciatura que embora tenham, em sua maioria, sólida formação, nas diversas áreas da Física, geralmente não possuem adequada formação em didática das ciências e em educação, de modo geral.

Camargo, S. (2003). Prática de Ensino de Física: marcas de referenciais teóricos no discurso de licenciandos. 207f. Faculdade de Ciências, Dissertação (Mestrado em Educação para a Ciência). UNESP, Bauru.

Charlot, B. (1986). A mistificação pedagógica: realidades sociais e processos ideológicos na teoria da educação, 2 ed. Guanabara: Rio de Janeiro.

Fracalanza, H. (1992). O que sabemos sobre os livros didáticos para o ensino de ciências no Brasil. 293f. Universidade Estadual de Campinas, Faculdade de Educação Campinas, São Paulo, Tese (Doutorado em Educação).

Freire, P. (1987). Pedagogia do oprimido, $22^{a}$ ed. Paz e Terra: Rio de Janeiro.

Gil Pérez, D. (1991). ¿Que hemos de saber y saber hacer los profesores de ciencias? Intento de Síntesis de las aportaciones de la investigación didáctica. En Enseñanza de las Ciencias, v.9, No.1, pp. 69-77.

Gonzales, C. (1976). Para que ensinar física em paises subdesenvolvidos. En Revista Brasileira de Ensino de Física, São Paulo, v. especial (1): pp. 42-72, jul. 
Gómes, A. P. (1992) O pensamento prático do professor: a formação do professor como profissional reflexivo. In: Nóvoa, Antônio (org). Os professores e a sua formação. Lisboa: Publicações Dom Quixote. pp. 93-114.

Killner, G. (1998). Ensino de Ciências: novas tendências, velhos hábitos. In: Ciclo de Seminários em Ensino de Ciências, Matemática e Educação Ambiental, 8, Resumos.... Faculdade de Ciências, Universidade Estadual Paulista, Câmpus de Bauru.

Moreira. M. (2000). A Ensino de Física no Brasil: Retrospectiva e Perspectivas. En Revista Brasileira de Ensino de Física, vol. 22, n 1 , Março.

Orlandi, E. P. (2002). Análise De Discurso: Princípios e Procedimentos. Campinas: Pontes Editores.

Orlandi, E. P. (2001). A linguagem e seu funcionamento: as formas do discurso. $4^{\mathrm{a}}$. ed. Pontes Editores: Campinas

Orlandi, E. P. (1996). Interpretação: Autoria, Leitura e Efeitos do trabalho Simbólico. $2^{\mathrm{a}}$. ed. Editora Vozes: Petrópolis, R. J.
Pecheux, M. (1990) O discurso: estrutura ou acontecimento. Pontes Editores: Campinas

Pecheux, M. (1994) Ler o arquivo hoje. In: Orlandi, E.P (Org.); Gestos de Leitura. Editora da UNICAMP: Campinas, pp. 55-66.

Saltiel. E., y Viennot, L. (1985). Que aprendemos de las semejanzas de las ideas históricas y el razonamiento espontáneo de los estudiantes? En Enseñanza de las Ciencias, v. 3, n. 1, pp. 137-144.

Schön, D. A. (1992) Formar professores como profissionais reflexivos. In: Nóvoa, Antônio (Org). Os professores e a sua formação. Publicações Dom Quixote: Lisboa, pp. 78-91.

Villani. A. (1984). Reflexões sobre o ensino de Física no Brasil: Práticas, Conteúdos e Pressupostos. En Revista de Ensino de Física, São Paulo, v.6, n. 2, p. 76-95, dezembro.

ARTíCULO RECIBIDO: 01-09-2004

Y APROBADO: 17-06-2005 